\title{
Schizophrenia: neuroinflammation, neurodegeneration or neurodevelopment? A genetic overview
}

\author{
Esquizofrenia: neuroinflamação, neurodegeneração ou neurodesenvolvimento? \\ Visão global dos aspectos genéticos
}

\section{Gabriel Berlingieri Polho ${ }^{1}$, Vanessa de Jesus Rodrigues de Paula ${ }^{2}$}

Polho GB, De-Paula VJR. Schizophrenia: neuroinflammation, neurodegeneration or neurodevelopment? / Esquizofrenia: Neuroinflamação,

ABSTRACT: Schizophrenia is a devastating mental illness and its etiology is still largely unknown. Several gene mapping studies suggest that schizophrenia is a complex disorder, with a cumulative impact of variable genetic effects coupled with environmental factors. There is evidence that schizophrenia could be a neurodegenerative, neuroinflammatory or neurodevelopmental disorder. Neuropsychological data indicate neurocognitive functions are relatively stable over time after illness onset, whereas morphological data indicate a degenerative process; potential roles of neuroinflammation in the etiology of psychiatric diseases including schizophrenia have also been suggested. Recent research indicates genetic overlap between schizophrenia and syndromes in which psychopathology manifests in childhood and that are often grouped together as 'neurodevelopmental disorders'. These findings challenge the etiological basis of current diagnostic categories and, together with evidence for frequent comorbidity, suggest that we should view the functional psychoses as members of a group that result in part from a combination of genetic and environmental effects on brain development and that are associated with specific and general impairments of cognitive function. The objective was to perform a systematic literature review of articles on genetics of schizophrenia relating to neurodegeneration, neuroinflammation and neurodevelopment. After proper filter, we included 40 studies and reviewed each finding and its relevance to the hypotheses. We can conclude that the evidence points to schizophrenia as a neurodevelopmental disease with the direct presence of factors related to neuroinflammation and neurodegeneration.

Keywords: Schizophrenia/genetics; Neurodevelopmental disorders/ genetics; Pantothenate kinase-associated neurodegeneration/ genetics; Neurogenetic inflammation/genetics; Genetics.
RESUMO: Esquizofrenia é uma doença mental debilitante e sua etiologia é, em sua maior parte, desconhecida. Alguns estudos de mapeamento genético sugerem que esquizofrenia é uma doença complexa, com impacto acumulativo de fatores genéticos variáveis associados a fatores ambientais. Há evidência de que a esquizofrenia poderia ser uma doença neurodegenerativa, neuroinflamatória ou do neurodesenvolvimento. Dados neuropsicológicos indicam que funções cognitivas são relativamente estáveis no decorrer do tempo após o início da doença, enquanto dados morfológicos indicam processos degenerativos; papéis importantes da neuroinflamação na etiologia de doenças psiquiátricas, incluindo esquizofrenia, também foram sugeridos. Pesquisas recentes indicam sobreposição entre esquizofrenia e síndromes cuja fisiopatologia se manifesta na infância e são em geral agrupadas como "doenças do neurodesenvolvimento". Estes achados desafiam a base etiológica das categorias atuais de diagnóstico e, juntamente com a evidência de comorbidade frequente, sugerem que devemos ver as psicoses como membros do grupo que resulta em parte da combinação de efeitos genéticos e ambientais no desenvolvimento do cérebro e que estão associados a prejuízos específicos e gerais da função cognitiva. O objetivo foi realizar uma revisão sistemática da literatura de trabalhos em genética da esquizofrenia relacionados a neurodegeneração, neuroinflamação e neurodesenvolvimento. Após buscas específicas, incluímos 40 estudos e revisamos cada achado e sua relevância para a hipótese. Nós concluímos que a evidência aponta para esquizofrenia como uma doença do neurodesenvolvimento com presença direta de fatores relacionados a neuroinflamação e neurodegeneração.

Descritores: Esquizofrenia/genética; Transtornos do neurodesenvolvimento/genética; Neurodegeneração associada a pantotenatoquinase/genética; Inflamação neurogênica/genética; Genética.

Psychiatry - Monographs Awards. XXXV COMU - Congresso Médico Universitário da FMUSP, São Paulo, 14-16 out. 2016.

1. Laboratory of Neuroscience (LIM 27), Department and Institute of Psychiatry, Faculty of Medicine, University of Sao Paulo, Brazil. E-mail: gabriel.polho@usp.br

2. $\mathrm{PhD}$. Genetics and Pharmacogenetics Unit (LIM 23), Department and Institute of Psychiatry, Faculty of Medicine, University of Sao Paulo, Brazil. E-mail: vanessaj@usp.br

Corresponding Author: Vanessa de Jesus Rodrigues de Paula /Gabriel Berlingieri Polho. Institute of Psychiatry, University of São Paulo (IPQ, University of São Paulo School of Medicine). São Paulo, SP, Brazil. E-mails: vanessaj@usp.br, gabriel.polho@usp.br. 


\section{INTRODUCTION}

Cchizophrenia is a common psychiatric $\checkmark$ disorder, with an estimated prevalence of $1 \%$ in general population and high financial and social costs $^{1}$. The clinical manifestations are divided in positive symptoms (hallucination, delusion), negative symptoms (social withdrawal, lack of emotion) and cognitive decline (memory dysfunction), which are used in the diagnosis of schizophrenia, since there is no biomarker for the disease. The physiopathology of the disease is unknown, whereas several theories have emerged to explain its features: neurotransmitters dysfunction (several neurotransmitters have been related to schizophrenia, such as dopamine, serotonin, GABA and glutamate), neurodevelopment abnormalities, neurodegenerative disorder, accelerated aging syndrome, neuroinflammation disorder, among other described models ${ }^{2,3,4}$.

The oldest theory was elaborated in 19th- century by Kraepelin, who described the disease as "dementia praecox", since young patients progressively, deteriorated its cognitive functions while suffering from hallucinations ${ }^{2}$. This description approximates schizophrenia to clinical progression of known neurodegenerative processes, such as Alzheimer's disease, creating basis for the development of neurodegeneration hypothesis for schizophrenia ${ }^{3}$. Furthermore, some evidence showing enlargement of ventricles during disease-years, glutamate excitoxicity, oxidative damage and other chemical similarities with recognized degenerative processes support this theory. However some authors argument, as it occurred with Kraepelin afterwards, neurodegeneration model would not explain alone all the clinical features of schizophrenia, including why a subset of patients improve after treatment ${ }^{2,3}$.

The second theory elaborated was neurodevelopment. Despite it had been first proposed in 1873 by Thomas Clouston, who described clinical features of the "adolescent insanity", only in mid-1980 it resurged, with more robust evidence. Existence of premorbid stage, cranial-facial abnormalities, neuroimaging findings in first-episode patients, increased risk for the disease when obstetric and gestational complications support the theory of neural development disorder. This model, however, do not explain satisfactorily why the onset is during adolescence/young adults period and how a subgroup of patients recover after treatment. Detailing the development hypothesis was tried to address these problems, such as the neonatal ventral hippocampal lesion ${ }^{2}$, the progressive developmental disease ${ }^{3}$ and the "two-hit" hypothesis ${ }^{4}$.

Lastly, neuroinflammation model surged more recently when, for example, Stevens introduced the idea of inflammatory markers in cerebral spinal fluid of schizophrenia patients and correlated this with the neuropathology ${ }^{5}$. The most substantial evidence for this hypothesis is the findings of statically significant MHC classes in three independent Genome Wide Association Studies (GWAS) 6 . Furthermore, a history of autoimmune disorders and maternal infections increase the risk of the disease; and, although inconsistent, some report activated microglia in schizophrenia brain samples ${ }^{6}$.

Classifying schizophrenia as a neurodevelopment, neurodegenerative or neuroinflammation disorder would be a step toward more specific therapies, as it would facilitate and guide future researches for diseasemodifying agents and symptoms treatment, besides improving prevention measures.

\section{METHODS}

Systematic reviews in the Medline literature database through PubMed for the keywords "schizophrenia (MesH Terms) AND neurodevelopment", "schizophrenia (MeSH Terms) AND neurodegeneration" and "schizophrenia (MeSH Terms) AND neuroinflammation".

Firstly, the papers were filtered for language (only English), publication date (5 years), species (only humans) and article type (excluding reviews). Then, the articles were manually selected by title and abstract. The papers left were separated into categories: genetics, neuroimaging, neurochemistry or clinic. In this review, only the works in the category "genetics" were analyzed. Lastly, we also excluded papers not available.

\section{RESULTS}

During the search, 649 articles were selected for the first search step of studies related to neurodegeneration, neuroinflammation and neurodegeneration. Only work with original genetics of human data remained in the study.

For the neurodegeneration search, 25 articles were found and 5 included in the study; for the neuroinflammation search, 14 articles were found and 3 included in the review; for the neurodevelopment search, 96 articles were found and 32 included (Figure 1).

Despite being found in one of the three searches, some papers had overlapping results with other hypothesis. Therefore, the findings will be described within each hypothesis, but may contain articles found during the search of the other model.

In order to facilitate the description of the results, we divided the findings according to the type of variable tested, which we classified in: Single Nucleotide Polymorphism (SNP), mRNA, miRNA, epigenetic and others.

The most abundant literature regarding the development hypothesis is on single nucleotide polymorphisms (SNPs), since we found 21 studies on the topic ( 2 GWAS). In the neurodegeneration search, 
only 3 studies were found; no study was present in the neuroinflammation search.

We found 4 studies from neurodevelopment search, 3 studies from neuroinflammation search, and 1 study from neurodegeneration search regarding mRNA analysis in schizophrenia subjects. The common methodology (except for two studies) was to analyze mRNA levels in patients with schizophrenia of genes already involved in one of the three categories (inflammation, development and degeneration).

Only two papers studied epigenetic in schizophrenia, both found in the neurodevelopment search. The studies performed Genome wide DNA methylation analysis: the first in discordant twins for schizophrenia or bipolar disorder; the second for a limited sample of the same diseases.

The only paper on miRNA topic was found in the neurodevelopment search, which showed significance for one specific miRNA.

Finally we also found 1 study on DNA damage during neurodegeneration search; 2 studies on rare variants and 2 studies on protein levels in neurodevelopment search.

Following, we describe each study included and its implications in each model.
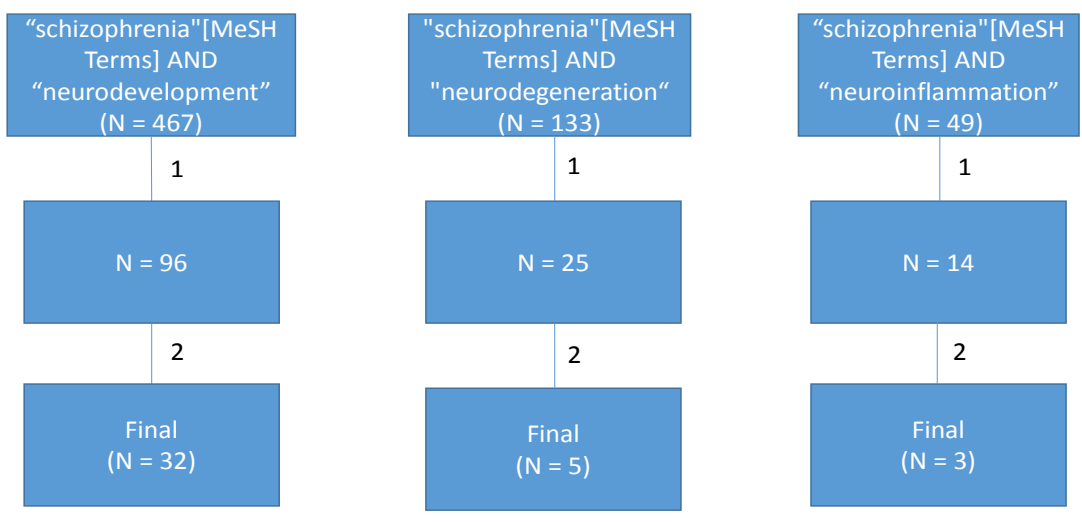

1. Filtered for language (only English), publication date (5 years), species (only humans) and article type (excluding reviews)

2. Manual extraction by title and abstract and selection of the Category "Genetic"

Figure 1. Hlow diagrama

\section{Neurodegeneration}

Schizophrenia is a behavioral disorder, which reveals itself in neurocognitive dysfunction. Neuropsychological data indicate these functions are relatively stable over time after illness onset, whereas morphological data indicate a neurodegenerative process. Determining whether schizophrenia is a neurodegenerative illness with progressive structural changes in the brain after presentation of the illness, or a neurodevelopmental disorder starting in early life, is of significant importance for understanding the pathophysiology.

In one study, authors found that CRP40/mortalin-2 mRNA was reduced in schizophrenia at first episode and in chronic stage, possibly reflecting increased cell stress or protein damage ${ }^{7}$. Heat shock proteins ${ }^{8}$ are stimulated by protein denaturation which can occur in thermal stress, oxidative stress, hypoxia, mitochondrial collapse etc. Proteotoxic stress is a hallmark of neurodegenerative disorders and heat shock proteins are differentially regulated in this conditions (some are overexpressed, others are underexpressed).

In the same rationale, which alleges cellular damage to the cell, one study showed greater DNA damage in drug-naïve schizophrenia subjects, when compared to control, though the DNA machinery was preserved ${ }^{9}$.

The hypothesis-free epigenetic experiments also support the cellular damage evidence. Authors described altered methylation pattern at sites previously associated with degeneration disorder, such as Hnrnpal gene (hypomethylated), regulated together with stressinduced phosphorylation signals. Some mutations have already been associated with amyotrophic lateral sclerosis and frontotemporal dementia ${ }^{10}$. GWAS performed in association with cognitive measures in schizophrenia have not showed any significant SNP for cognitive impairment in the disease, but a polygenic score with little variance explanation. This method of analysis permits the identification of the most statistically relevant SNPs for the condition tested, in a large SNP pool (commonly 
hundreds of thousands SNPs), independently of the examiners hypothesis.

Individual SNP studies have implicated Saitohin gene $^{11}$ and ERBB4 pathway $^{12}$ in the pathogenesis of schizophrenia. Saitohin is in linkage disequilibrium with tau gene, which codes a well-described protein probably involved in Alzheimer's disease. According to Bosia et al. ${ }^{11}$, it may predict poorer cognitive function in the subset of schizophrenia patients with the risk allele. ERBB4 pathway, in the other hand, is described in both cell death and cell growth metabolism. SNPs in ERBB4 or NRG1 (Neuregulin-1 - described in more details in "Neurodevelopment") may alter transcription factor bond and therefore promote metabolism disturbances, but these results do not elucidate whether this is important for apoptosis and/or neurogenesis in schizophrenia.

\section{Neuroinflammation}

Some evidence suggests the significance of neuroinflammation and immunogenetics in schizophrenia. Microglia is the major players in innate immunity in the CNS. They respond quickly to even minor pathological changes in the brain and may contribute directly to the neuronal degeneration by producing various proinflammatory cytokines and free radicals. In many characteristics, the neuropathology of schizophrenia is closely associated with microglial activation ${ }^{13}$.

Microglial activation (microgliosis) is often accompanied by reactive astrocyte activation (astrogliosis), and indicates neuroinflammation. However, evidence for either microgliosis or astrogliosis in schizophrenia is inconsistent. In the study performed by Catts et al. ${ }^{14}$, the subset of schizophrenia patients with increased expression of inflammatory markers (such as cytokines) showed increased expression of astrogliosis-associated mRNA when compared to subset of schizophrenia patients with less expression of inflammatory markers, but they did not show difference between the overall sample of schizophrenia subjects and control. Apparently, antipsychotic might reduce gliosis and alter astrocyte morphology.

Another gliosis-associated gene, IFITM, mRNA was analyzed ${ }^{15}$. Interferon-induced transmembrane protein (IFITM) is a viral restriction factor produced by stimulus of cytokines and interferon. Mouse models for mild chronic inflammation (for example, NF-kB deficiency) have increased levels of IFITM and decreased levels of GABA neurons. The study found the same results in patients with schizophrenia (increased levels of IFITM mRNA in cortical blood vessels and an association with GABA neurons decrease). These findings would support the theory of neuroinflammation in schizophrenia. However, another paper rejected the evidence of neuroinflammation ${ }^{16}$, by comparing microarray data of schizophrenia and classical inflammatory conditions (such as multiple sclerosis, inflammatory bowel disease and dermatomyositis). They concluded that the mRNA sets could be separated in two distinct groups: the known inflammatory conditions and the neuropsychiatric conditions. The possible explanation for the fact that some inflammatory molecules are found in the neuropsychiatric diseases is that parallel cellular signaling mechanisms exist between immune system and nervous system. In other words, the same molecules have different roles in the systems, for example: complement receptor has a role in immune activation as well as in synaptic 'pruning' ${ }^{17}$.

Finally, considering the hypothesis of increased cytokine secretion in schizophrenia, one study evaluated SNPs in IL6 and IL6 receptor genes, but found no association with the disease ${ }^{18}$.

\section{Neurodevelopment}

Rosanoff proposed an association of schizophrenia with complications of pregnancy and delivery as early as 1934. According to these, the etiology of schizophrenia may involve pathologic processes, caused by both genetic and environmental factors, which begin before the brain approaches its adult anatomical state in adolescence ${ }^{3}$.

Several genes in the context of neurodevelopment have been studied, as we can see in the Table 1. However, only a few SNPs had nominal statistical association with the disease, whereas some have been connected with neuroimaging differences and cognitive function in both control and schizophrenia subjects.

Associations of SNPs with schizophrenia in smallscale studies were found for SNPs in GSK3B ${ }^{21}$, BRAP ${ }^{19}$, DLCK1 ${ }^{20}$, MYT1L ${ }^{22}$ and BDNF ${ }^{23}$, but not for NTNG1. Some were validations of previous Genome WideAssociation studies (GWAS) results.

Moreover, SNPs in genes important for neurodevelopment have been correlated with neuroimaging variances $^{26-32}$ and cognitive impairment ${ }^{24,25,33}$. Specific genes had effects in both healthy control and schizophrenia subjects; other had effects only in schizophrenia individuals or the effects on schizophrenia and control were contrary. These findings might not indicate an essential role of the genes in the genesis of schizophrenia, but may demonstrate the importance of neural development variances on the great clinical variety of schizophrenia.

Trying to eliminate hypothesis bias, some authors performed GWAS. The first concluded that one SNP in EIF2AK4 gene was associated with response to haloperidol $^{34}$. We must consider, however, that it did not reach GWAS statistical significance and the two samples tested showed opposite tendencies. The second GWAS performed found no association between any SNP and one of the clinical dimensions in schizophrenia (positive symptoms, negative symptoms and mood disturbances). In this study, only polygenic scores including thousands of genes could predict case-control status. 
Table 1. Tested genes and studies' conclusions

\begin{tabular}{|c|c|c|}
\hline Authors & Genes & Conclusion \\
\hline Zhang et al. ${ }^{19}$ & BRAP & One SNP was found to be associated with schizophrenia after validation \\
\hline Håvik et al..$^{20}$ & DCLK1 & $\begin{array}{l}\text { SNPs found in previous GWASs seems to be associated with schizophrenia as well as with attention deficit } \\
\text { disorder, IQ and memory }\end{array}$ \\
\hline Li et al. ${ }^{21}$ & GSK3B & $\begin{array}{l}\text { Three SNPs were associated with schizophrenia and one of them was found to change the transcriptional } \\
\text { activity of GSK3B }\end{array}$ \\
\hline Li et al. ${ }^{22}$ & MYT1L & Difference allelic frequencies were found for one SNP between schizophrenia subjects and control \\
\hline Zakharyan et al. ${ }^{23}$ & $\begin{array}{l}\text { NTNG1 and } \\
\text { BDNF }\end{array}$ & $\begin{array}{l}\text { Allelic frequencies of one SNP from BDNF was found to be overrepresented in schizophrenia and associated } \\
\text { with earlier onset. No differences were found in one NTNG1 SNP }\end{array}$ \\
\hline Carmel et al. ${ }^{24}$ & $\begin{array}{l}\text { COMT and } \\
\text { PRODH }\end{array}$ & $\begin{array}{l}\text { COMT SNP affects executive function in patients with 22q11.2 deletion syndrome. No correlation was found } \\
\text { for PRODH SNP studied }\end{array}$ \\
\hline Lennertz et al. ${ }^{25}$ & SHANK 1 & $\begin{array}{l}\text { SNP form SHANK1 gene was associated with decreased working memory in schizophrenia and high-risk } \\
\text { subjects but not in healthy volunteers }\end{array}$ \\
\hline Kido et al. ${ }^{26}$ & $\begin{array}{l}\text { YWHAE and } \\
\text { DISC1 }\end{array}$ & $\begin{array}{l}\text { Significant interaction between SNP from YWHAE and left insula, right putamen and right hippocampus } \\
\text { volume. No association between SNP from DISC1 and gray matter volume }\end{array}$ \\
\hline Takahashi et al. ${ }^{27}$ & DISC1 & $\begin{array}{l}\text { Association of DISC1 SNP and some neurodevelopmental markers in magnetic resonance image (MRI), such } \\
\text { as cavum septic pellucid and orbitofrontal cortex morphology }\end{array}$ \\
\hline Takahashi et al. ${ }^{28}$ & YWHAE & $\begin{array}{l}\text { The orbitofrontal gyrus pattern of schizophrenia subjects was different from control subjects. On the latter } \\
\text { group, one SNP was associated with the protective pattern }\end{array}$ \\
\hline Nishimura et al. ${ }^{29}$ & EGR3 & $\begin{array}{l}\text { Genotype for one SNP from ERG3 was associated with smaller oxyHb increase (hypoactivation) in dorsolateral } \\
\text { prefrontal cortex on both schizophrenia and control }\end{array}$ \\
\hline Tosato et al. ${ }^{30}$ & NRG1 & $\begin{array}{l}\text { In a sample of individuals with schizophrenia, subjects with one NRG1 SNP had smaller superior temporal } \\
\text { gray and white matter volumes }\end{array}$ \\
\hline Sim et al. ${ }^{31}$ & ARVCF & $\begin{array}{l}\text { Specific haplotypes for SNPs from ARVCF gene were correlated with caudate volume in MRI and } \\
\text { neurocognitive measurements. The combination of the haplotypes studied also had different behaviors in } \\
\text { schizophrenia and control (recessive } x \text { dominant, respectively) }\end{array}$ \\
\hline Wirgenes et al. ${ }^{32}$ & TCF4 & TCF4 SNPs were correlated with cognitive dysfunction and decreased cerebellar volume in schizophrenia \\
\hline Tost et al. ${ }^{33}$ & NRG3 & $\begin{array}{l}\text { NRG3 SNP risk allele was correlated with increased dorsolateral pre frontal cortex activation (considered as } \\
\text { inefficiency) in healthy subjects but the inverse correlation was observed in the schizophrenia group }\end{array}$ \\
\hline
\end{tabular}

Maintaining the analysis of large-scale studies, another three papers were identified. The first tried to correlate sets of SNPs with connectivity within brain default mode, which may indicate the resting neuronal activity $^{35}$. This approach differed from GWAS as they used multivariate analysis instead of univariate analysis. In other words, they used clusters of interacting SNPs instead of calculating SNPs risk individually. Another interesting difference was the fact they used the brain default mode and not the diagnosis itself as the variable in the analysis. This means they used an intermediate phenotype, instead of the "final" complex phenotype, which might be the result of interactions from several other intermediate phenotypes. This approach has been considered in the literature as an alternative of studying schizophrenia itself, because of the complexity and diversity of the disease $^{36}$. The authors found several groups of SNPs correlated with each pattern of brain default mode, mainly related to neurogenesis, cell adhesion, axon guidance and inflammation, among others. The second study intended to validate subsets of neural development-related genes found in previous GWAS datasets and verified enrichment of significative $\mathrm{p}$-values in the neurodevelopment subset ${ }^{37}$. Finally, the third study also collected the evidence from previous GWAS and created metabolic pathways related to the genes products ${ }^{38}$. Both neurodevelopment and neuroinflammation processes were represented by the pathways elaborated, but the authors emphasize the possible role of Toll-like receptor family as a connection between the various pathways whose disruption may be involved in schizophrenia.

Rare variants (less than $5 \%$ of frequency in the population) may also take part in schizophrenia etiology. A genome wide study found increased proportion of rare variants in the schizophrenia subjects and analysis was enriched for genes expressed in fetal brain ${ }^{39}$. In another study of rare variations, no association was found for mutations in PTPRA gene and schizophrenia or autism, in spite of some variants found only in the people with the diseases may produce damage to protein production. PTPRA is believed to be critical to neurodevelopment and animal models support association with both autism and schizophrenia ${ }^{40}$.

Existing biomolecular methodologies permit the analysis not only of DNA, but also of its products. In the papers associated to neurodevelopment, one study concluded that GABA related mRNA disturbances in schizophrenia seem to not be related with illness chronicity, but may be the consequence of blunted or incomplete neurodevelopment ${ }^{41}$. The differences found between 
schizophrenia subjects and control go in the opposite direction of changes in expression during development (for example, vGAT, GAD 67 and parvalbumin mRNA levels increased during postnatal development, whereas they were decreased in schizophrenia subjects compared to control). However, since the study used post mortem brain sample of chronic patients, it cannot be ruled out that GABA related mRNA are disturbed during early stages of the disease.

Changes in mRNA Neuregulin 1, which is a recognized growth factor, during development have also been reported ${ }^{42}$. The authors describe the mRNA pattern from prenatal to old age of different NRG1 subtypes. Some SNPs of neuregulin increase the risk of schizophrenia in multiple populations and a specific polymorphism at NRG1 was associated with altered expression pattern of one NRG1 isoform in prenatal and early postnatal periods. Therefore, the link between genetic risk and the disease might be its interference in neurodevelopment trajectory of NRG1 mRNA subtypes. Moreover, diminished NRG1induced AKT phosphorylation in lymphoblast was associated with smaller hippocampal volume in firstepisode schizophrenia ${ }^{43}$.

FMR1 gene has also been studied in the context of schizophrenia ${ }^{44}$. This gene encodes for FMRP, which is the fragile $\mathrm{X}$ mental retardation protein (causative of a known inherited mental disability), but FMR1 mRNA levels did not differ between schizophrenia and control subjects. However, FMRP was decreased in schizophrenia and associated with lower IQ and early onset of illness, possibly due to abnormal translation or increased degradation. Another study replicated the finding of reduced FMRP levels and connected this result with reduced contrast sensitivity in schizophrenia subjects, perhaps by influencing visual pathway development ${ }^{45}$. Thus, FMRP reduced levels might represent the neurodevelopment feature of schizophrenia.

Transcriptome made on human induced pluripotent cell and neural progenitor cell from one patient with schizophrenia showed 228 genes altered only in the neural differentiation of the cells from the schizophrenia subject, from which ten were related to schizophrenia in previous studies and most are important to neurodevelopment or plasticity. Additionally, the authors performed a co expression analysis of these genes with data of adult brain samples of individuals with schizophrenia (compared to adult brain samples of control), from which some of the "hub genes" found exclusively on the schizophrenia group have also been associated with neural development disorders (such as CIT and LIN7A) ${ }^{46}$.

Epigenetic evidence supports the theory of neurodevelopment in schizophrenia. Complementary results were found in the studies, since the first found no difference in global DNA methylation between the twins tested $^{47}$, but disease-associated differences at specific CpG islands; the second found a DNA globally hypomethylated with regions of hypermethylation ${ }^{48}$. Both performed pathway enrichment analysis, revealing pathways related to brain development, axon guidance, cell adhesion, metabolism and long-term potentiation.

In these studies, individual genes have also been implicated to the disease, such as: ST6GALNAC1 (hypomethylated) and Npas1 (hypermethylated). ST6GALNAC1 is known to be differentially regulated at key periods of neurodevelopment; Npas 1 has already been described as an important mediator of neuron subtypes generation $^{49}$ in pre-natal brain development.

Some precautions must be taken when analyzing these results. Both used subjects in treatment and with chronic disease, which can affect the methylation pattern. Besides, both used small samples, which increase false negative results.

miRNA has also been implicated in schizophrenia pathology. In one study, the only miRNA that survived rigorous statistical analysis for differential expression in dorsolateral prefrontal cortex of post mortem brain tissue ${ }^{50}$ was miRNA-132, despite some others had already been related to schizophrenia in previous studies ${ }^{51}$. This miRNA is regulated by NMDA signaling and CREB/ERK pathway.

In the same study, authors identified negative association between miRNA-132 and mRNA from Dpyls3 and Dnmt3a, in different times during mouse brain development, as well as negative association between miRNA-132 and DNMT3A and GATA2 protein levels in culture cells. Therefore, Dpyls3, Dnmt3a and Gata2 are probable targets of miRNA-132, mainly during the adolescence period, when miRNA-132 levels increase. Described hypofunction of NMDA signaling (mediated by glutamate) in the disease and interaction between NMDAR and miRNA-132 may explain the abnormal miRNA-132 levels in schizophrenia. Indeed, mouse pups treated with NMDA antagonist (simulating what might happen in the disease) were found to have downregulated miRNA-132 and the effect remained in adulthood. This pattern may be related to the known NMDA "pruning" that occur in normal adolescence but may be deregulated in schizophrenia patients ${ }^{52}$.

Overall, most evidence suggest a main role of neurodevelopment in the genesis of schizophrenia, even though some participation of genetic factors involved in neurodegeneration may also occur.

\section{Limitations}

Several limitations of this study and of the data interpretation must be considered. First, some of the studies used small samples, insufficient to avoid type I error. This is a known problem in the field of neurosciences and a recent review showed that the median statistical 
power in neuroscience is $21 \%$, which can produce false negatives, results with low predictive positive value, and exaggerate the magnitude of the effect ${ }^{53}$.

Second, schizophrenia is a complex disorder and many authors consider it as a syndrome of different diseases $^{54}$. Interestingly, several authors found subsets of schizophrenia patients with different biological behavior from the other, such as SNPs found only in a group of patients with worse performance or determined neuroimaging variance. Recently, it was proposed that rare variants were present in subgroups of patients and determined phenotypic distinct subtypes, for example carriers of variants in SLC39A13 showed severe negative symptoms and global cognition deficit, suggesting a subtype more related to development; carriers of ARMS/ KIDINS220 variants showed cognitive deficits and good educational attainment, suggesting degeneration over the years ${ }^{55}$.

The high variability among the patients complicates the generalization of genetic markers for the disease. One of the possible strategies used to overcome this difficulty is the use of endophenotypes, which are intermediate and measurable phenotypes filling the gap between the clinical manifestations of the psychiatric disorder and genetic $^{36}$. However, this approach was considered only in a few articles.

Third, most of the evidence used case-control methodologies, but not patient cohorts. The cohort design permits to clearly calculate the relative risk of each genetic marker and its implications on neuroimaging, neurochemistry and cognitive decline described above.

Fourth, large scale studies are still hard to be interpreted. In GWASs, for example, despite statistical analysis provide a group of associated SNPs, their biological manifestations and implications cannot be assured and must be confirmed by posterior experiments.

Finally, the methodology used in this systematic review might have excluded studies possibly related to one of the theories, as only the papers with studies in humans were assessed and the quantity of studies found in each search was divergent.

\section{DISCUSSION}

The most abundant literature found studied neurodevelopment-related genes and their role in schizophrenia. Only few authors have prospected genetic markers for neurodegeneration and neuroinflammation.

Examining the evidence detected, SNPs of genes important to neurodevelopment have been associated with schizophrenia or neuroimaging/cognitive aspects of the disease, including worsening/improvement of these aspects in the carriers. In other words, these genes increase the risk of the disease or interfere in the prognosis. Even hypothesis-free experiments (such as GWAS) have found evidence for this.

SNPs are static genetic information and can determine or not functional implications (for example if there is linkage disequilibrium with a truly risk gene). Epigenetic, mRNA and miRNA studies, on the other hand, show dynamic information and are closer to cell function at determined moment. Hypothesis-free studies on miRNA, mRNA and epigenetic showed evidence for disturbance in regulation of neurodevelopment-related genes. However, one genome-wide methylome also showed differential methylation pattern for neurodegeneration-related gene. We must consider, however, mRNA of inflammationrelated and degeneration-related genes differentially expressed, as analyzed by specific studies.

Interestingly, we observed there was some overlap between the genes claimed to be related to one of the three theories, such as NRG1. Furthermore, many authors did not distinguish one main process, but linked, for example, neuroinflammation and neurodegeneration as a consequence. In the literature of schizophrenia, unifying models have emerged, for example "progressive neurodevelopment disease" (linking neurodevelopment and neurodegeneration), "development neuroinflammation" 56 (linking inflammation and development), proposing a better explanation of clinical features and imaging/chemical alterations. In our study, we can consider genetic evidence also fits unifying models: altered development signals during prenatal phase, inflammation markers at onset and gene predisposition to degeneration process, manifesting in the chronic phase. We must consider, however, no article proved this progression, but only showed indirect evidence for each of them and some combinations; "inflammation" markers and its role in inflammation or synaptic maintenance (as suggested earlier) are still to be explained.

\section{CONCLUSION}

Considering the papers on physiopathology genetic studies of schizophrenia, we can conclude that the most substantial evidence support the hypothesis of neurodevelopment abnormality. However, when considered all the evidence, we must not ignore the possible coexistence of both neuroinflammation and neurodegeneration in the course of schizophrenia, whose roles are still to be explained and linked. In all analyzed studies, the neurodevelopmental theory is the most robust on the results and may be accompanied by neurodegeneration and neuroinflammation way. We can conclude the complexity of schizophrenia allows to suggest that the three mechanisms are present, with the neurodevelopment as the predominant factor. 
Polho GB, De-Paula VJR. Schizophrenia: neuroinflammation, neurodegeneration or neurodevelopment?

Funding source: This work was supported by FAPESP (Fundação de Amparo à Pesquisa do Estado de São Paulo, processo número 2014/27129-6; 2016/01302-9).

Conflicts of interest: Authors declare no conflicts of interest.

Acknowledgements: The present study was financially supported by the Fundação de Amparo à Pesquisa do Estado de São Paulo (FAPESP, São Paulo, 2014/27129-6 and 2016/01302- 9).

\section{REFERENCES}

1. National Institute of Mental Health. Schizophrenia [cited 2016 Jun 27]. Available from: http://www.nimh.nih.gov/ health/topics/schizophrenia/index.shtml.

2. Tseng KY, Chambers RA, Lipska BK. The neonatal ventral hippocampal lesion as a heuristic neurodevelopmental model of schizophrenia. Behav Brain Res. 2009;204(2):295-305. doi: 10.1016/j.bbr.2008.11.039.

3. Gupta S, Kulhara P. What is schizophrenia: a neurodevelopmental or neurodegenerative disorder or a combination of both? A critical analysis. Indian J Psychiatry. 2010;52(1):21-7. doi: 10.4103/0019-5545.58891.

4. Iritani S. What happens in the brain of schizophrenia patients?: an investigation from the viewpoint of neuropathology. Nagoya J Med Sci. 2013;75:11-28. Available from: https:// www.ncbi.nlm.nih.gov/pmc/articles/PMC4345712/.

5. Stevens JR. The neuropathology of schizophrenia. Psychol Med. 1982;12:695-700. https://doi.org/10.1017/ S0033291700048996.

6. Kahn RS, Sommer IE. The neurobiology and treatment of first-episode schizophrenia. Mol Psychiatry. 2015;20(1):8497. doi: $10.1038 / \mathrm{mp} .2014 .66$.

7. Groleau SE, Lubarda J, Thomas N, Ferro MA, Pristupa ZB, Mishra RK, et al. Human blood analysis reveals differences in gene expression of catecholamine-regulated protein 40 (CRP40) in schizophrenia. Schizophr Res. 2013;143(1):2036. http://dx.doi.org/10.1016/j.schres.2012.10.034

8. Leak RK. Heat shock proteins in neurodegenerative disorders and aging. J Cell Commun Signal. 2014;8(4):293-310. doi: 10.1007/s12079-014-0243-9.

9. Muraleedharan A, Menon V, Rajkumar RP, Chand P. Assessment of DNA damage and repair efficiency in drug naïve schizophrenia using comet assay. J Psychiatr Res. 2015;68:47-53. doi: 10.1016/j.jpsychires.2015.05.018.

10. Auburger G, Gispert S, Brehm N. Methyl-Arginine Profile of Brain from Aged PINK1-KO+A53T-SNCA Mice Suggests Altered Mitochondrial Biogenesis. Parkinsons Dis. 2016;2016:4686185. doi: 10.1155/2016/4686185.

11. Bosia M, Buonocore M, Guglielmino C, Pirovano A, Lorenzi C, Marcone A, et al. Saitohin polymorphism and executive dysfunction in schizophrenia. Neurol Sci. 2012;33(5):1051-6. doi: 10.1007/s10072-011-0893-9.

12. Agim ZS, Esendal M, Briollais L, Uyan O, Meschian M, Martinez LAM, et al. Discovery, Validation and characterization of Erbb4 and Nrg1 haplotypes using data from three genome-wide association studies of schizophrenia. PLoS One. 2013;8(1): e53042. doi: 10.1371/journal. pone. 0053042 .

13. Laskaris LE, Di Biase MA, Everall I, Chana G, Christopoulos
A, Skafidas E, et al. Microglial activation and progressive brain changes in schizophrenia. Br J Pharmacol. 2016;173(4):66680. doi: 10.1111/bph.13364.

14. Catts VS, Wong J, Fillman SG, Fung SJ, Shannon Weickert C. Increased expression of astrocyte markers in schizophrenia: Association with neuroinflammation. Aust N Z J Psychiatry. 2014;48(8):722-34. doi: 10.1177/0004867414531078.

15. Siegel BI, Sengupta EJ, Edelson JR, Lewis DA, Volk DW. Elevated viral restriction factor levels in cortical blood vessels in schizophrenia. Biol Psychiatry. 2014;76(2):160-7. doi: 10.1016/j.biopsych.2013.09.019.

16. Filiou MD, Arefin AS, Moscato P, Graeber MB. "Neuroinflammation" differs categorically from inflammation: transcriptomes of Alzheimer's disease, Parkinson's disease, schizophrenia and inflammatory diseases compared. Neurogenetics. 2014;15(3):201-12. doi: 10.1007/ s10048-014-0409-x.

17. Stephan AH, Barres BA, Stevens B. The complement system: an unexpected role in synaptic pruning during development and disease. Annu Rev Neurosci. 2012;35:369-89. doi: 10.1146/annurev-neuro-061010-113810.

18. Kapelski P, Skibinska M, Maciukiewicz M, Pawlak J, Permoda-Osip A, Twarowska-Hauser J. Family-based association study of interleukin 6 (IL6) and its receptor (IL6R) functional polymorphisms in schizophrenia in the Polish population. J Neuroimmunol. 2015;285:62-7. doi: 10.1016/j.jneuroim.2014.09.019.

19. Zhang F, Liu C, Xu Y, Qi G, Yuan G, Cheng Z, et al. A twostage association study suggests BRAP as a susceptibility gene for Schizophrenia. PLoS One. 2014;9(1):e86037. doi: 10.1371/journal.pone.0086037.

20. Havik B, Degenhardt FA, Johansson S, Fernandes CPD, Hinney A, Scherag A, et al. DCLK1 variants are associated across schizophrenia and attention deficit/hyperactivity disorder. PLoS One. 2012;7(4):1-12.

21. Li M, Mo Y, Luo X jian, Xiao X, Shi L, Peng Y, et al. Genetic association and identification of a functional SNP at GSK3 $\beta$ for schizophrenia susceptibility. Schizophr Res. 2011;133(13):165-71. doi: 10.1016/j.schres.2011.09.013.

22. Li W, Wang X, Zhao J, Lin J, Song XQ, Yang Y, et al. Association study of myelin transcription factor 1-like polymorphisms with schizophrenia in Han Chinese population. Genes Brain Behav. 2012;11(1):87-93. doi: 10.1111/j.1601-183X.2011.00734.x.

23. Zakharyan R, Boyajyan A, Arakelyan A, Gevorgyan A, Mrazek F, Petrek M. Functional variants of the genes involved in neurodevelopment and susceptibility to schizophrenia in an Armenian population. Hum Immunol. 2011;72(9):746-8. http://dx.doi.org/10.1016/j.humimm.2011.05.018. 
24. Carmel M, Zarchi O, Michaelovsky E, Frisch A, Patya M, Green T, et al. Association of COMT and PRODH gene variants with intelligence quotient (IQ) and executive functions in 22q11.2DS subjects. J Psychiatr Res. 2014;56(1):28-35. http://dx.doi.org/10.1016/j.jpsychires.2014.04.019.

25. Lennertz L, Wagner M, Wölwer W, Schuhmacher A, Frommann I, Berning J, et al. A promoter variant of SHANK1 affects auditory working memory in schizophrenia patients and in subjects clinically at risk for psychosis. Eur Arch Psychiatry Clin Neurosci. 2012;262(2):117-24. doi: 10.1007/ s00406-011-0233-3.

26. Kido M, Nakamura Y, Nemoto K, Takahashi T, Aleksic B, Furuichi A, et al. The polymorphism of YWHAE, a gene encoding 14-3-3epsilon, and brain morphology in schizophrenia: a voxel-based morphometric study. PLoS One. 2014;9(8):1-9. doi: 10.1371/journal.pone.0103571.

27. Takahashi T, Nakamura M, Nakamura Y, Aleksic B, Kido M, Sasabayashi D, et al. The Disrupted-in-Schizophrenia-1 Ser704Cys polymorphism and brain neurodevelopmental markers in schizophrenia and healthy subjects. Prog NeuroPsychopharmacology Biol Psychiatry. 2015;56:11-7. http:// dx.doi.org/10.1016/j.pnpbp.2014.07.005.

28. Takahashi T, Nakamura Y, Nakamura Y, Aleksic B, Takayanagi Y, Furuichi A, et al. The polymorphism of YWHAE, a gene encoding 14-3-3epsilon, and orbitofrontal sulcogyral pattern in patients with schizophrenia and healthy subjects. Prog Neuro-Psychopharmacology Biol Psychiatry. 2014;51:166-71. http://dx.doi.org/10.1016/j. pnpbp.2014.02.005

29. Nishimura Y, Takizawa R, Koike S, Kinoshita A, Satomura Y, Kawasaki S, et al. Association of decreased prefrontal hemodynamic response during a verbal fluency task with EGR3 gene polymorphism in patients with schizophrenia and in healthy individuals. Neuroimage. 2014;85:527-34. http://dx.doi.org/10.1016/j.neuroimage.2013.08.021

30. Tosato S, Bellani M, Bonetto C, Ruggeri M, Perlini C, Lasalvia $\mathrm{A}$, et al. Is neuregulin 1 involved in determining cerebral volumes in schizophrenia? Preliminary results showing a decrease in superior temporal gyrus volume. Neuropsychobiology. 2012;65(3):119-25. doi: $10.1159 / 000330584$

31. Sim K, Chan W-Y, Woon P-S, Low H-Q, Lim L, Yang G-L, et al. ARVCF genetic influences on neurocognitive and neuroanatomical intermediate phenotypes in Chinese patients with schizophrenia. J Clin Psychiatry. 2012;73(3):320-6. http://europepmc.org/abstract/MED/22053977.

32. Wirgenes K V, Sønderby IE, Haukvik UK, Mattingsdal M, Tesli M, Athanasiu L, et al. TCF4 sequence variants and mRNA levels are associated with neurodevelopmental characteristics in psychotic disorders. Transl Psychiatry. 2012;2:e112. doi: 10.1038/tp.2012.39

33. Tost H, Callicott JH, Rasetti R, Vakkalanka R, Mattay VS, Weinberger DR, et al. Effects of neuregulin 3 genotype on human prefrontal cortex physiology. J Neurosci. 2014;34(3):1051-6. doi: 10.1523/JNEUROSCI.3496-13.2014.

34. Drago A, Giegling I, Schäfer M, Hartmann AM, Konte B, Friedl M, et al. Genome-wide association study supports the role of the immunological system and of the neurodevelopmental processes in response to haloperidol treatment. Pharmacogenet Genomics. 2014;314-9. doi: 10.1097/FPC.0000000000000052.

35. Meda SA, Ruaño G, Windemuth A, O’Neil K, Berwise C, Dunn SM, et al. Multivariate analysis reveals genetic associations of the resting default mode network in psychotic bipolar disorder and schizophrenia. Proc Natl Acad Sci USA . 2014;111(19):E2066-75. doi: 10.1073/pnas.1313093111.

36. Millard SP, Shofer J, Braff D, Calkins M, Cadenhead K, Freedman R, et al. Prioritizing schizophrenia endophenotypes for future genetic studies: An example using data from the COGS-1 family study. Schizophr Res. 2016; 174(1-3):1-9. doi: 10.1016/j.schres.2016.04.011.

37. Zhao Z, Webb BT, Jia P, Bigdeli TB, Maher BS, van den Oord E, et al. Association Study of 167 Candidate Genes for Schizophrenia Selected by a Multi-Domain EvidenceBased Prioritization Algorithm and Neurodevelopmental Hypothesis. PLoS One. 2013;8(7):e67776. doi: 10.1371/ journal.pone.0067776.

38. Crisafulli C, Drago A, Calabrò M, Spina E, Serretti A. A molecular pathway analysis informs the genetic background at risk for schizophrenia. Prog Neuro-Psychopharmacology Biol Psychiatry. 2015;59:21-30. http://dx.doi.org/10.1016/j. pnpbp.2014.12.009.

39. Loohuis LMO, Vorstman JAS, Ori AP, Staats KA, Wang $\mathrm{T}$, Richards AL, et al. Genome-wide burden of deleterious coding variants increased in schizophrenia. Nat Commun. 2015;6:7501. doi: 10.1038/ncomms8501

40. Xing J, Wang C, Kimura H, Takasaki Y, Kunimoto S, Yoshimi A, et al. Resequencing and association analysis of PTPRA, a possible susceptibility gene for schizophrenia and autism spectrum disorders. PLoS One. 2014;9(11):1-8. doi: 10.1371/ journal.pone.0112531.

41. Hoftman GD, Volk DW, Bazmi HH, Li S, Sampson AR, Lewis DA. Altered cortical expression of GABA-related genes in schizophrenia: Illness progression vs developmental disturbance. Schizophr Bull. 2015;41(1):180-91. doi: 10.1093/schbul/sbt178

42. Paterson C, Wang Y, Kleinman JE, Law AJ. Effects of schizophrenia risk variation in the NRG1 gene on NRG1-IV splicing during fetal and early postnatal human neocortical development. Am J Psychiatry. 2014;171(9):979-89. doi: 10.1176/appi.ajp.2014.13111518.

43. Szamosi A, Kelemen O, Kéri S. Hippocampal volume and the AKT signaling system in first-episode schizophrenia. J Psychiatr Res. 2012;46(3):279-84. http://dx.doi. org/10.1016/j.jpsychires.2011.12.005.

44. Kovács T, Kelemen O, Kéri S. Decreased fragile X mental retardation protein (FMRP) is associated with lower IQ and earlier illness onset in patients with schizophrenia. Psychiatry Res. 2013;210(3):690-3.

45. Kelemen O, Kovács T, Kéri S. Contrast, motion, perceptual integration, and neurocognition in schizophrenia: The role of fragile-X related mechanisms. Prog Neuro-Psychopharmacol Biol Psychiatry. 2013;46:92-7. http://dx.doi.org/10.1016/j. pnpbp.2013.06.017.

46. Maschietto M, Tahira AC, Puga R, Lima L, Mariani D, da Silveira Paulsen B, et al. Co-expression network of neuraldifferentiation genes shows specific pattern in schizophrenia. BMC Med Genomics. 2015;8(1):23. Available from: http:// www.biomedcentral.com/1755-8794/8/23. 
47. Dempster EL, Pidsley R, Schalkwyk LC, Owens S, Georgiades A, Kane F, et al. Disease-associated epigenetic changes in monozygotic twins discordant for schizophrenia and bipolar disorder. Hum Mol Genet. 2011;20(24):4786-96.

48. Li Y, Camarillo C, Xu J, Arana TB, Xiao Y, Zhao Z, et al. Genome-wide methylome analyses reveal novel epigenetic regulation patterns in schizophrenia and bipolar disorder. Biomed Res Int. 2015;2015.

49. Stanco A, Pla R, Vogt D, Chen Y, Mandal S, Walker J, et al. NPAS1 represses the generation of specific subtypes of cortical interneurons. Neuron. 2014;84(5):940-53. Available from: http://www.pubmedcentral.nih.gov/articlerender.fcgi? artid $=4258152 \&$ tool $=$ pmcentrez\&rendertype $=$ abstract.

50. Miller BH, Zeier Z, Xi L, Lanz TA, Deng S, Strathmann J, et al. MicroRNA-132 dysregulation in schizophrenia has implications for both neurodevelopment and adult brain function. Proc Natl Acad Sci. 2012;109(8):3125-30.

51. Perkins DO, Jeffries CD, Jarskog LF, Thomson JM, Woods K, Newman MA, et al. microRNA expression in the prefrontal cortex of individuals with schizophrenia and schizoaffective disorder. Genome Biol. 2007;8(2):R27. Available from: http://www.pubmedcentral.nih.gov/articlerender.fcgi?artid

Received: November 2, 2016

Accepted: January 20, 2017
$=1852419 \&$ tool $=$ pmcentrez\&rendertype $=$ abstract.

52. Keshavan MS, Anderson S, Pettegrew JW. Is schizophrenia due to excessive synaptic pruning in the prefrontal cortex? The Feinberg hypothesis revisited. J Psychiatr Res.;28(3):239-65. Available from: http://www.ncbi.nlm. nih.gov/pubmed/7932285.

53. Button KS, Ioannidis JP a, Mokrysz C, Nosek B a, Flint J, Robinson ESJ, et al. Power failure: why small sample size undermines the reliability of neuroscience. Nat Rev Neurosci. 2013;14(5):365-76. Available from: http://www.ncbi.nlm.nih. gov/pubmed/23571845.

54. Molina V, Blanco JA. A proposal for reframing schizophrenia research. J Nerv Ment Dis. 2013;201(9):744-52.

55. Kranz TM, Berns A, Shields J, Rothman K, Walsh-Messinger J, Goetz RR, et al. Phenotypically distinct subtypes of psychosis accompany novel or rare variants in four different signaling genes. EBioMedicine. 2016;6:206-14. Available from: http://www.ncbi.nlm.nih.gov/pubmed/27211562.

56. Meyer U. Developmental neuroinflammation and schizophrenia. Prog Neuropsychopharmacol Biol Psychiatry. 2013;42:20-34. Available from: http://www.ncbi.nlm.nih. gov/pubmed/22122877. 